\title{
Laboreal
}

Volume $6 \mathrm{~N}^{\circ} 1$ | 2010

Varia

\section{Etnografar o ruído em call centers : uma análise situada da actividade dos teleoperadores}

Etnografiar el ruído en los call centers : un análisis situado de la actividad de los teleoperadores

Ethnographier le bruit en centre d'appels : une analyse située de l'activité des téléopérateurs

Making an ethnographic study of noise in call centres : a situated analysis of call centre agents' work

\section{Karine Lan Hing Ting}

Tradutor. João Viana Jorge

\section{CpenEdition}

\section{Journals}

\section{Edição electrónica}

URL: http://journals.openedition.org/laboreal/9244

DOI: 10.4000/laboreal.9244

ISSN: 1646-5237

\section{Editora}

Universidade do Porto

\section{Refêrencia eletrónica}

Karine Lan Hing Ting, «Etnografar o ruído em call centers : uma análise situada da actividade dos teleoperadores », Laboreal [Online], Volume $6 \mathrm{~N}^{0} 1$ | 2010, posto online no dia 01 julho 2010, consultado o 10 outubro 2019. URL : http://journals.openedition.org/laboreal/9244 ; DOI : 10.4000/ laboreal.9244

Este documento foi criado de forma automática no dia 10 outubro 2019.

Laboreal está licenciado com uma Licença Creative Commons - Atribuição-NãoComercial 4.0 Internacional. 


\section{Etnografar o ruído em call centers : uma análise situada da actividade dos teleoperadores}

Etnografiar el ruído en los call centers : un análisis situado de la actividad de los teleoperadores

Ethnographier le bruit en centre d'appels : une analyse située de l'activité des téléopérateurs

Making an ethnographic study of noise in call centres : a situated analysis of call centre agents' work

\section{Karine Lan Hing Ting}

Tradução : João Viana Jorge

\section{REFERÊNCIA}

Artigo original : Lan Hing Ting, K. (2009). Ethnographier le bruit en centre d'appels : une analyse située de l'activité des téléoperateurs. Activités, 6 (2), pp. 100-118, http:// www.activites.org/v6n2/v6n2.pdf.

\section{Introdução}

1 Um call center é uma estrutura assente num telefone e na informática que permite uma comunicação directa e à distância entre um interlocutor (cliente actual ou potencial, aderente, utilizador...) e uma pessoa, comummente designada por teleoperador que representa a entidade que origina o call center (empresa, associação, comunidade local...) com o fito de responder da melhor maneira às necessidades dos utilizadores e/ ou de incrementar todo o tipo de relações com a clientela. Estes teleoperadores encontram-se reunidos num mesmo espaço físico, um "centro" organizado em "palcos" 
de tamanhos variáveis. $O$ centro onde teve lugar esta observação comportava quatro "palcos" acolhendo cada uma cerca de 125 pessoa : 100 teleoperadores - que mantêm as respectivas conversas telefónicas em simultâneo - 10 supervisores, 10 responsáveis de agência, dois assistentes de chefe de "palco" e um chefe de "palco".

2 Sejam franceses, americanos ou deslocalizados nos países emergentes, os centros têm a reputação de envolventes ruidosas de trabalho, onde, entre outras condições que os põem à prova (Taylor, Baldry, Bain, \& Ellis, 2003), os teleoperadores são submetidos a níveis sonoros elevados.

Este "constrangimento sonoro" resulta quase sempre, por um lado do ambiente sonoro da envolvente de trabalho (que segundo os peritos não deveria ultrapassar os $55 \mathrm{db}$ ) e por outro do volume sonoro gerado pelos auscultadores $(85 \mathrm{db})\left[{ }^{1}\right]$. Os investigadores que mediram os níveis acústicos nos call centers verificaram ainda que quanto maior o ruído ambiente mais os operadores tinham tendência para aumentar o volume dos auscultadores expondo-se assim a um risco auditivo e a uma situação de stress. Estudos de ergonomia e de medicina do trabalho recomendaram alocar 9 a $10 \mathrm{~m} 2$ por pessoa a fim de reduzir o ruído ambiente e também limitar o incómodo devido às interferências entre locutores (Planeau, \& Robinet, 2003). Todavia nem sempre essa recomendação é respeitada : $25 \%$ dos call centers franceses ultrapassariam os limiares admissíveis de nível sonoro (ibid).

Pude observar diversos tipos de call centers, franceses ou deslocalizados. Num deles, um centro interno de um fornecedor de acessos, os teleoperadores eram muito menos numerosos e dispunham de mais espaço de trabalho pessoal. Neste, o trabalho dos operadores é mais "individualizado"[2]. Ora o centro descrito neste artigo pode com efeito ser categorizado como "envolvente de trabalho ruidoso". o trabalho colectivo (Karsenty, \& Pavard, 1997 ; Benchekroun, 2000) entre supervisores e teleoperadores em função é, aí, subsequente, demarcado por práticas de cooperação (Heath, \& Luff, 1992), animadas, audíveis e portanto "ruidosas". Este centro é especializado em telemarketing subcontratando campanhas de prospecção, de diversos produtos e clientes. Os teleoperadores contactam particulares no seu domicílio - os chamados "potenciais" para lhes proporem uma oferta ou um produto comercial. As chamadas encadeiam-se, levando na maioria das vezes à recusa imediatamente a seguir à oferta que faz o teleoperador. As que finalizam favoravelmente, caracterizadas por um interesse claro por parte do cliente potencial prosseguem em sequências de trabalho colaborativo. $O$ segundo extracto analisado é um trabalho de validação, por um superior hierárquico, após uma chamada bem sucedida de uma teleoperadora, enquanto o primeiro extracto aparece entre duas chamadas de prospecção da operadora. Antes de abordar o exame desses dois extractos exponho de maneira geral as diferentes "produções" sonoras que pude observar neste centro. Essa apresentação situa o pano de fundo, a saber: os diferentes "ruídos" em call centers aparecem correntemente integrados como rotina no trabalho quotidiano. A seguir irei apresentar a orientação da pesquisa e os seus métodos que irão contribuir para perspectivar a opção por uma análise dos dois extractos em particular.

\section{2. "Etnografar" os diferentes "ruídos"}

5 Resulta da observação que as ocorrências sonoras (Thibaud, 1991) no "palco" são numerosas e fazem parte da rotina do trabalho diário. A presença prolongada do 
etnógrafo no "palco" permite-lhe adquirir progressivamente as competências de "membro" (Garfinkel, \& Sacks, 1970). Assim o etnógrafo consegue dar sentido às diferentes emissões de som permitindo-lhe distinguir melhor as diversas manifestações de "ruído" no "palco", apreciar a sua variedade, apreender a sua especificidade e pertinência na actividade e não as encarar apenas como "ruído". De facto, os "palcos" deste call center são frequentemente comparados com uma colmeia. A centena de teleoperadores está envolvida nas respectivas conversas telefónicas, digita nos teclados (Zimmerman, 1992), clica os botões do rato, roda as suas cadeiras, conversam com os seus colegas entre as chamadas ou colaboram verbalmente com os seus superiores hierárquicos. Por vezes atraem a atenção dos superiores com intimações sonoras: estalam os dedos ou batem palmas audíveis a vários metros de distância.

Figura 1 : Vista de conjunto de um " palco » do call center

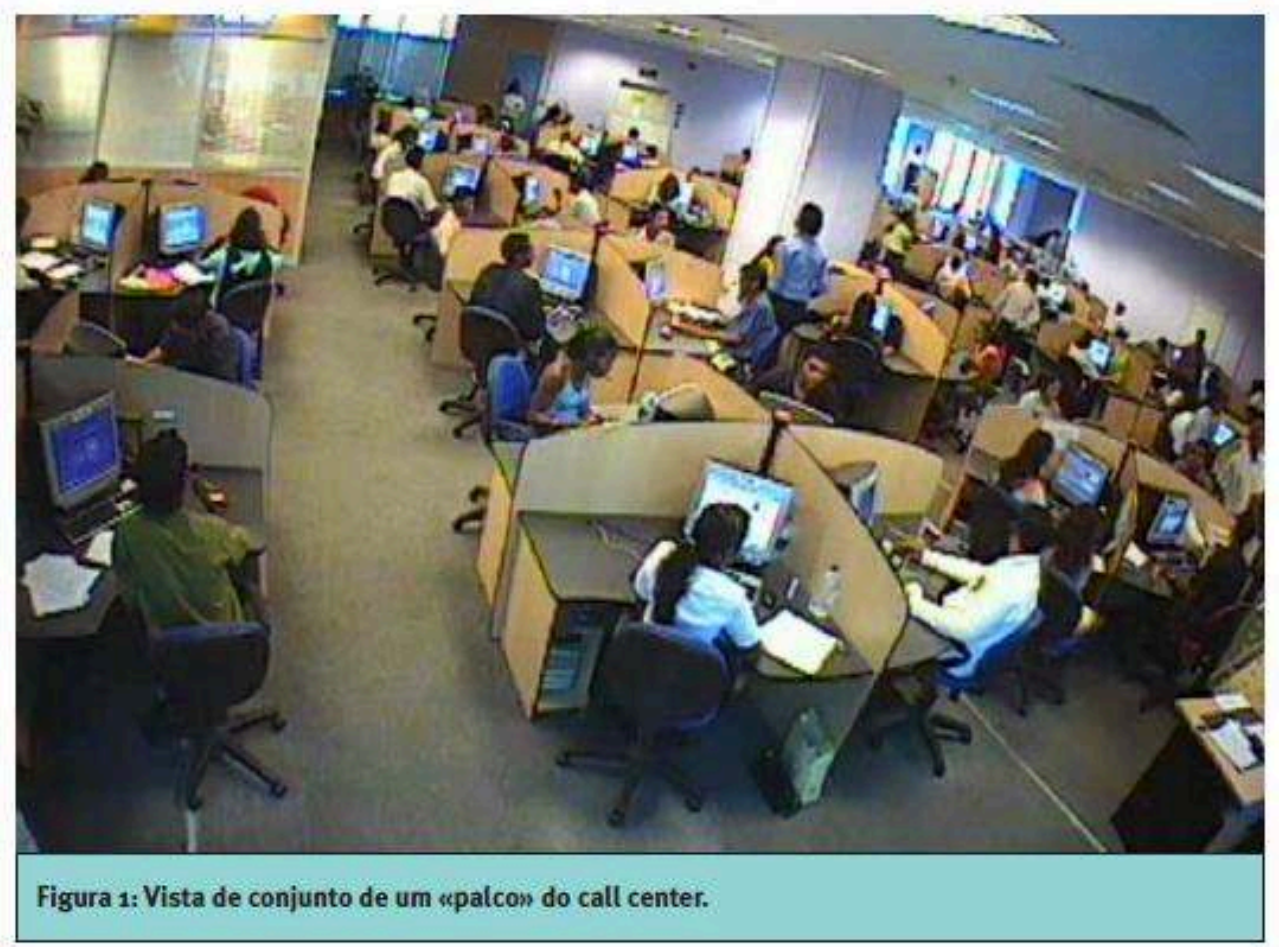

6 Alguns superiores ou responsáveis de agência deslocam-se no "palco" constituindo-se em auxiliares volantes quando são solicitados por aquelas intimações sonoras. 0 cochichar - em que o supervisor dita as réplicas a um teleoperador (Fig. 2) do qual seguiu a conversa telefónica para ajudar a finalizar uma venda - é frequentemente dito em voz alta à distância pelo supervisor que se encontra no seu posto. 
Figura 2 : 0 supervisor, de pé, prestes a cochichar as réplicas ao teleoperador, a partir do seu posto

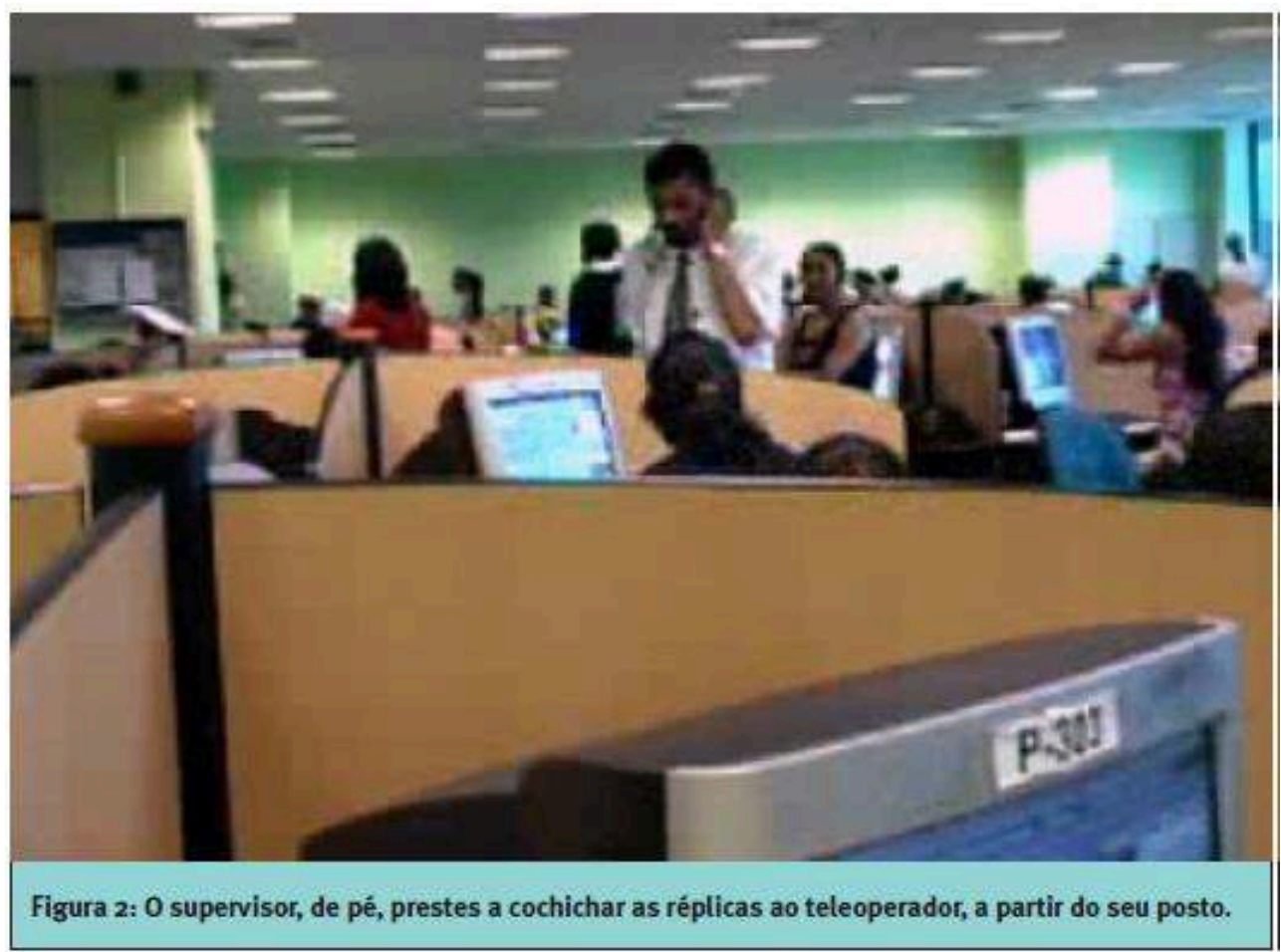

7 Aquilo que qualifico de "produzir ruído voluntariamente", acontece igualmente em momentos específicos. Quando um teleoperador consegue um encontro ou uma venda, é vulgar que o conjunto da sua equipa, uma dezena de participantes, o aplaudam por iniciativa do supervisor. Identicamente, a reunião da equipa da manhã é a oportunidade para fazer o ponto dos resultados da véspera. Aplaudir-se durante a reunião da equipa e lançar gritos de alegria constitui tanto uma exultação como a motivação da equipa no arranque da jornada de trabalho.

Compreender as diversas ocorrências de "ruído" implica estudar o fenómeno a partir do que é visível e descritível [3] como constituindo um "ruído" para os participantes no decurso da acção e demonstrável pela análise a partir de orientações concretas por parte dos participantes. O modo de inquérito reflexivo (Lynch, 2000) aplicado à démarche etnográfica pretende que as observações efectuadas em call centers não sejam produto de técnicas sociológicas especializadas, mas a mobilização de um raciocínio prático do senso comum (Garfinkel, 1967). Nisso a distinção clássica em ergonomia, entre "ruído" como factor de nocividade e o "sinal" que constitui um recurso (Ombredane, \& Faverge, 1955) revela-se útil para esta análise fina conduzida no terreno (em situação real de trabalho). Numa démarche próxima da minha, Jean-Paul Thibaud (1991) "etnografou" nomeadamente as práticas comunicacionais, em estaleiro, dos operários da construção civil com e pelos sons em acção, coordenando-se pela utilização dos sons próprios a esta profissão. Os sons não são unicamente um epifenómeno ou uma consequência secundária da actividade. A envolvente acústica é uma característica essencial da acção, indissociável da actividade. Não é dado a priori, “já lá" : é produto, expressão e condição das práticas sociais. A problemática é então, não o acompanhamento acústico das actividades sociais mas a concretização prática da envolvente acústica (Thibaud, 1998). 
Ver-se-á na análise dos dois extractos, da concretização das "ocorrências sonoras" (ibid) e dos "ruídos", de que modo a demarcação entre ambos não é dada a priori mas emerge da situação. São os participantes que os categorizam como recurso, pela cooperação, ou como entrave à actividade decorrente, como elemento perturbador que incomoda a comunicação telefónica com o cliente ou a interacção colaborativa no "palco" (Kryter, 1985) ou que representa um constrangimento sonoro. Tratar-se-á de ter em conta o tratamento dos sons pelos próprios participantes : do seu ponto de vista e na lógica organizacional da sua envolvente de trabalho e na concretização da sua actividade laboral.

10 A etnografia constituiu sempre um método preferencial em antropologia social e em etnologia e é também um dos métodos correntemente utilizados pelos ergónomos (Blanket, \& Poupa, 2007) tratando-se de estudos sobre call centres, enquanto a pesquisa sociológica tendeu a dar prioridade aos métodos de sondagens e análises estatísticas. Desde há uma dezena de anos tende a verificar-se nas ciências sociais uma reviravolta metodológica : a etnografia ganha influência tornando-se uma abordagem de inquérito popular. A razão principal desta mudança parece ser o reconhecimento da importância da subjectividade na vida social (Francis, \& Hester, 2004, p. 22), com a adopção de um ponto de vista émico (Pyke,1967 ; Winkin, 1981) ou o que os sociólogos inter-accionistas de Chicago chamaram "o ponto de vista do actor". Encarar as pessoas enquanto "actores" em situação, detentoras de um conjunto de competências e de práticas partilhadas com base na experiência de trabalho com os outros, requer a procura de novos meios para compreender a relação entre as pessoas, a tecnologia, as exigências do trabalho e os constrangimentos organizacionais (Bannon, 1991). A etnografia é então o método privilegiado para auxiliar a concepção dos locais de trabalho "tecnologizados", como os "centros de coordenação" de que os call centers fazem parte. Ponto de encontro entre as ciências sociais e a informática, a corrente do Computer Supported Cooperative Work preconiza a concepção de novas tecnologias promotoras de práticas colaborativas das equipas. O CSCW inspirou-se em larga medida na etnografia etnometodológica na linha dos trabalhos pioneiros de Lucy Suchman (1987). O carácter contextual e não teórico da etnometodologia - cuja agenda rigorosamente descritiva obriga a produzir descrições ricas de trabalho em contexto (Shapiro, 1994) revelou-se de grande valor para os designers (Kensing, \& Simonsen, 1997). Acedendo ao detalhe concreto do trabalho realizado em situação, os designers podem então captar "o que na realidade se passa", "o que coloca de facto problemas" no decurso de uma actividade laboral e portanto conseguem imaginar que ferramentas poderiam ser concebidas para ajudar os actores a resolver os seus problemas (Hughes, Randall, \& Shapiro, 1992). A concepção de sistemas colaborativos comporta um interesse central para o trabalho, o cumprimento de procedimentos formais e uma rotina organizacional tendo em vista as contingências quotidianas do trabalho ; aquilo com que o etnógrafo contribui para o design e para a concepção é o conhecimento das práticas cooperativas de trabalho através das quais o trabalho é organizado pelos participantes seja em copresença ou distribuídos no espaço e no tempo (Crabtree, 2003). Afastando-se das regras e dos planos como estruturas de controlo da acção que não determinam nem o cumprimento das actividades laborais nem o modo como a coordenação se efectua, este artigo encara a análise das práticas laborais nos call centers, enquanto "centros de coordenação" (Suchman, 1997), aos quais os investigadores da corrente dos Workplace Studies (Heath, Knoblauch, \& Luff, 2000 ; Heath, \& Luff, 2000) se interessaram (Zimmerman, 1992 ; Whalen, 1995). 


\section{Métodos e orientação de pesquisa}

11 A démarche etnográfica (Crabtree, 2003) e a abordagem naturalista do "ramo vídeo de análise de conversa" (ten Have, 1999), ambos de inspiração etnometodológica, implicam que se aborde o ruído de acordo com o interesse e as contingências na realização da actividade, quer dizer em termos da sua efectiva postura em prática (Leplat, \& Hoc, 1983) na realidade do trabalho (Béguin, 2007). $O$ interesse central da etnometodologia incide no carácter situado e localmente efectivado da ordem social. Sendo a vida social produzida "do interior" pelos membros da sociedade, a tarefa da etnometodologia consiste em identificar os métodos de tal produção a partir de estudos empíricos "de baixo para cima" (Hester, \& Francis, 2000). Os trabalhos etnometodológicos principalmente os de análise da conversação mostraram assim a preferência pelas transcrições feitas a partir de registos, primeiro áudio e a seguir vídeo (Goodwin. 1981). Esses registos vídeo das actividades situadas no seu enquadramento corrente são produzidos como dados audiovisuais naturalmente organizados no seio de uma perspectiva naturalista iniciada por Harvey Sacks (Mondada, 2008). Podem assim captar e salvaguardar os fenómenos supervenientes de maneira naturalmente organizada na sua envolvente quotidiana e rotineira, dito de outro modo, em situação real de trabalho. A agenda analítica da análise da conversação implica descrever as estruturas organizacionais da conduta que mobilizam de maneira multimodal e sistemática os recursos gramaticais, prosódicos, gestuais e visuais. São examinadas tal como mobilizadas pelos participantes na organização local da acção, sensíveis às contingências do contexto [4].

12 Estes dados vídeo - etnográficos recolhidos por múltiplas câmaras, permitem examinar a posteriori certos detalhes multimodais que a visão ou o ouvido do etnógrafo, em situação, não conseguem captar integralmente, ou que um registo áudio não permitiria abordar. Assíncronos com a observação no terreno, os dados dão acesso i) à conversa telefónica com o cliente potencial à qual o etnógrafo não pode aceder durante a observação, ii) às contribuições verbais e às orientações dos participantes para o ruído (gestos, olhar), iii) aos conteúdos do ecrã - movimentos do rato e mensagens em discussão instantânea, iv) ao intercâmbio entre os participantes presentes. Em conjunto, as duas etapas duma análise sequencial desse intercâmbio (ten Have, 1999) que são o registo e depois a transcrição fina das sequências seleccionadas de acordo com a sua pertinência, permitem aceder, repetidamente, não só aos detalhes da complexa organização de determinadas actividades laborais mas também à conversa, a verbalização através da qual o trabalho se concretiza.

13 Antes de abordar a análise dos dois extractos per se parece-me pertinente precisar a minha escolha analítica ao tratar estes dois extractos em detalhe. 0 objectivo desta análise não é produzir conhecimentos generalizáveis e exaustivos sobre o ruído nos call centers. Visa descrever com precisão a orientação dos participantes numa dada situação e a captar - o que Garfinkel (1967) designa por "thingness", "haecceity" o essencial duma situação. Um fenómeno analítico não é dado de forma abstracta ; é o contexto que faz da ocorrência de um ruído um fenómeno único ; a ordem encontra-se no detalhe. Compreender "o whatness" de uma situação, o que no fundo ela é, implica analisar as qualidades e características que fazem de uma dada situação uma situação particular. O que implica, em substância, evitar as generalizações a propósito das 
práticas laborais e explicar as envolventes do trabalho e o decurso de acções específicas. O método consiste então em analisar casos únicos (Schegloff, 1987) de um dado fenómeno pertinente e em mostrar como as implicações produtivas de tais práticas, tal como a sua ordem, se tornam visíveis. Trata-se, analiticamente, não de uma acumulação sistemática de conhecimentos mas de uma re-especificação dos objectos e dos produtos de trabalho técnico como realizações locais (Clayman, 1995). Nessa base focalizo a análise em dois extractos em que o ruído emerge como pertinente descrevendo com precisão os elementos distintivos de cada um destes fenómenos. Trata-se de tomar estas análises por aquilo que são : descrições detalhadas de um dado fenómeno (ruidoso) e que não é compreensível senão tendo em conta o contexto no qual cada um deles emerge de forma situada. Deste modo, esta análise permite compreender precisamente de que modo um ruído específico se torna pertinente para os participantes em cada um desses dois extractos.

\section{A tematização do eco nos auscultadores}

O primeiro extracto é uma tematização de eco oriundo dos auscultadores, sob a forma de queixa verbal que a teleoperadora (TO) dirige ao seu supervisor (Sup, Norbert) entre duas chamadas. A transcrição começa no momento em que, durante a sua chamada, ela envia a Ketty, a responsável pela agência, uma mensagem via discussão instantânea (no ecrã) para lhe perguntar o número de vendas finalizadas naquele "palco". Em retorno recebe uma mensagem de Ketty referindo que foi ouvida, antes de receber a resposta à pergunta. Estas actividades de escrita-envio-leitura das mensagens escritas aparece em paralelo com a actividade principal falar ao telefone com o cliente potencial - mostrada no rectângulo. A queixa sobre o eco nos auscultadores surge durante o tempo em que se processa a próxima chamada e é dirigida ao seu supervisor (sentado à sua direita, na mesma ilha e que se vê de frente nas imagens abaixo, envergando uma camisa azul). Ela dirige-se-lhe em crioulo transcrito a bold (negrito) e cuja tradução se apresenta em itálico. 
Extrato 1 : queixa e solicitação relativas ao eco oriundo do auscultador
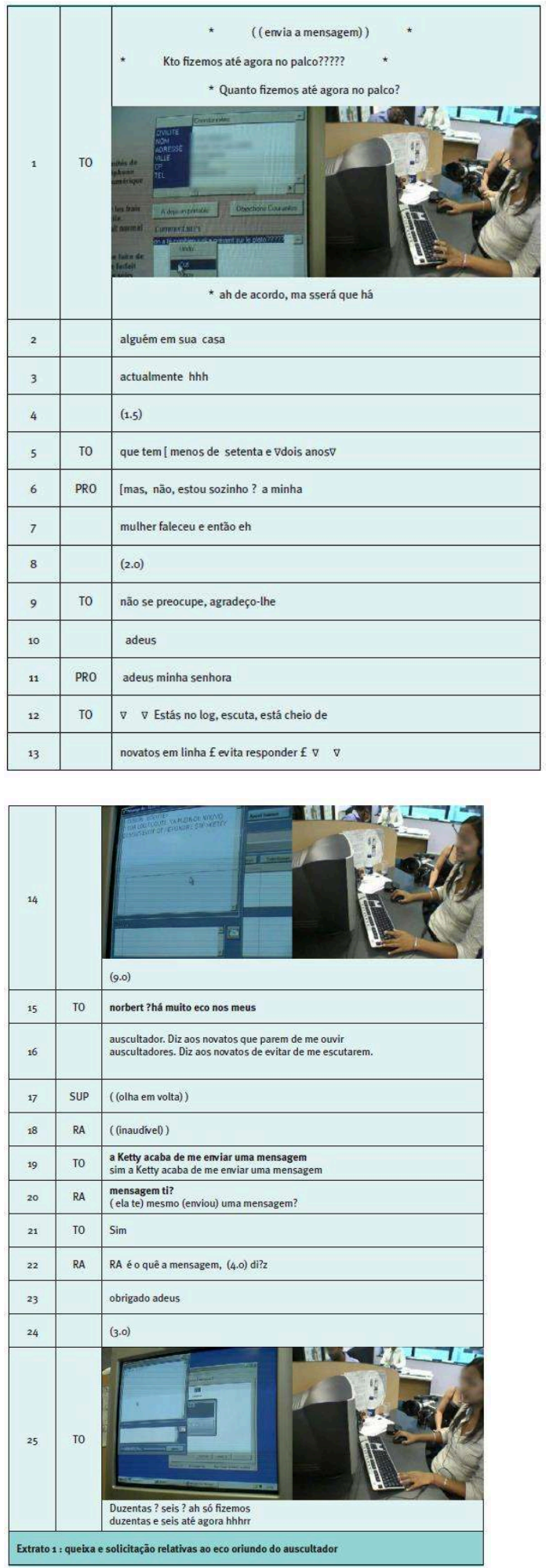

15 A teleoperadora está ainda em chamada quando recebe esta mensagem de Ketty, responsável pela agência. Linha 4 : é visível dado o seu silêncio (1,5 segundos), o franzir das sobrancelhas e a direcção do olhar, que ela começou a ler a mensagem pop-up [5] logo que esta apareceu. Empenhada ao mesmo tempo na sua actividade principal de chamada de prospecção, aquela interacção telefónica é ligeiramente perturbada: a 
pausa intra-frase na linha 4 permite ao clientepotencial a recusa mais fácil da proposta, indiciada pelo "não" da linha 6. Após o término da chamada, linha 12, lê em voz alta a mensagem que acaba de receber antes de fazer deslizar para o fundo do ecrã a respectiva janela (linha 14, foto à esquerda). Nove segundos depois, enquanto espera a ligação da sua próxima chamada, desactiva o microfone levantando-o [ $\left.{ }^{6}\right]$ e formula a queixa, em crioulo das Maurícias, tendo como tema o eco oriundo dos auscultadores. A tradução literal, em francês, da queixa, e depois, da solicitação é "Norbert, os meus auscultadores fazem um eco enorme. Diz aos novatos que evitem estar a escutar-me". Com efeito a prática rotineira neste call center (...) é a de que os novos teleoperadores, acabados de recrutar e ainda em formação "façam escutas". Estes últimos sentam-se num posto e ouvem no auscultador as chamadas dos teleoperadores experimentados [ $\left.{ }^{7}\right]$ que estão em "modo de escuta" (linha 12), quer dizer ligados de modo a poderem ser ouvidos. Quanto maior é o número de pessoas a ouvir as suas chamadas mais notório é o eco e potencialmente mais incomodativo para a sua conversa telefónica. Nesse momento, na ocorrência, "está cheio de novos em linha" (linha 12). o eco perturba potencialmente a comunicação tanto no que se refere à operadora como ao cliente potencial, à distância : constitui portanto, duplamente, um "ruído" e como tal é tratado pelo supervisor. À tematização do eco, seguido pelo pedido que lhe é dirigido, o supervisor endireita-se na cadeira e varre o palco com o olhar à procura de novos teleoperadores, fontes potenciais do eco ruído. Torna assim visível que compreendeu o pedido e que vai eventualmente tentar resolver o problema. Embora ela se dirija, nomeando-o, a Norbert, a intervenção da operadora é igualmente ouvida, compreendida e tratada por um responsável da agência (que não Ketty) - RA na transcrição - que se encontra nas proximidades. A sua primeira intervenção oral, linha 17, não é audível. Em todo o caso segue-se uma discussão entre o responsável da agência e a teleoperadora incidindo na mensagem enviada por Ketty (um topic talk Maynard, 1980) que precedeu a tematização do eco nos auscultadores. Na linha 19 a operadora afirma: "Sim, Ketty acaba de me enviar uma mensagem" ao que ele responde "(ela) (enviou-te) mesmo uma mensagem", o que ela confirma. Na linha 22 ele põe uma questão respeitante ao conteúdo exacto da mensagem. Ela não lhe responde. Compreende-se pelo tratamento que a operadora dá à questão e pela direç̧ão do seu olhar que ela mantém dirigido àquele último que o responsável da agência se re empenhou na sua actividade principal junto de outra teleoperadora em funções, a quem dá instruções em situação (linha 22-23).

16 O facto da conversa a propósito do eco e da mensagem não prosseguir aponta para um outro que é o de ser a situação de trabalho e o envolvimento na actividade principal as chamadas - que é privilegiado. Do mesmo modo, o eco não é tratado como absoluto, como sendo um ruído que incomodaria a operadora em termos de constrangimento físico ao nível da sua audição, mas sim em termos de entrave durante a comunicação telefónica. Foi a própria operadora que categorizou o eco como incomodativo da audibilidade da conversa telefónica quando lhe coloquei a questão, surgida logo após esta sequência da interacção aqui transcrita. $O$ ruído é então tratado pelos membros da "palco" exclusivamente quando constitui um incómodo para a concretização da actividade que são os telefonemas. Aliás, mesmo que o eco já dure há várias chamadas [8] ela não o menciona antes ; a mensagem eniada por Ketty parece, na sequência, ser o elemento desencadeador. Se, por exemplo, o eco lhe fizesse mal aos ouvidos ela tê-lo-ia mencionado mais cedo e de modo diferente. Compreender esta sequência requer pois uma análise multimodal da interacção e das multi-actividade (Datchary \& Licoppe, 
2007 ; Mondada, 2008) de cada participante tal como dos seus envolvimentos e dos diferentes suportes comunicacionais. De facto, a interacção que surge no telefonema com o cliente (linhas 1 a 11), cara a cara com os colegas ou os superiores hierárquicos (linhas 15 a 22) e por escrito com Ketty, a responsável da agência (linhas 1,12 a 15 e 25) tornam-se, à vez ou simultaneamente, pertinentes em termos de focalização da atenção da teleoperadora. Compreender a organização da actividade laboral, o agenciamento entre os múltiplos envolvimentos adoptando modos de interacção diferentes, requer uma abordagem interaccional centrada na sequencialidade dos intercâmbios (Sacks, Schegloff, \& Jefferson, 1974) que o registo vídeo permite preservar com a sua temporalidade (ten Have, 1999; Relieu, Licoppe, \& Lan Hing Ting, no prelo), mas também uma recolocação em contexto organizacional destas práticas de comunicação.

17 Assim, uma análise sequencial da conversa não permitiria compreender todos os aspectos desta sequência tendo os auscultadores como tema. Parece essencial que a análise mobilize (não só) a caracterização que a própria operadora faz do eco nos auscultadores durante a curta "entrevista" espontânea que se seguiu a esta sequência (o eco perturba a audibilidade da comunicação telefónica), mas também o seu conhecimento do pano de fundo (Duranti, 2001 ; Maynard, 2003) respeitante às práticas de trabalho habituais, às categorias profissionais dos participantes [ $\left.{ }^{9}\right]$ e às regras [10]. Uma etnografia do terreno, relativamente longa e aprofundada, combinando a tomada de apontamentos, as discussões informais com os agentes para compreender a sua actividade e os registos audiovisuais, permitem integrar na análise todas as dimensões contextuais pertinentes para a actividade. Ao mesmo tempo é claro que o contexto não deve constituir um quadro determinante para a interacção. Trata-se então de interpretar e compreender um ciclo de palavras sobre o tema ruído, ou uma orientação, seja ela interaccional, corporal ou gestual, de forma situada, no contexto do cumprimento daquela particular actividade laboral (Suchman, 1987).

Deste modo, o eco nos auscultadores que a teleoperadora ouve - e para o qual nem ela própria nem o seu supervisor nem o responsável de agência se orientam considerandoo como um constrangimento sonoro - também não deve ser tratado pelo analista simplesmente como um "ruído". Mais do que um simples ruído o eco está relacionado com a actividade em curso. Desse ponto de vista o eco constitui uma "informação acústica" (Thibaud, 1998) como o som emitido pelas teclas de um teclado quando premidas. Com efeito o eco é produzido pela dupla escuta e constitui para a operadora uma indicação sonora que a informa de que os seus telefonemas estão a ser ouvidos pelos novatos. Este eco ganha sentido no contexto dos procedimentos habituais de trabalho e constitui um recurso informativo para a operadora. Ela orienta-se, na sua solicitação, para o que o eco implica em termos de escuta dupla e não para o eco por si só. Do ponto de vista dos participantes, o eco nos auscultadores faz portanto parte da organização do trabalho no "palco" e não é devido a uma simples falha técnica ou a uma má regulação. Todavia, seria possível imaginar, de um ponto de vista ergonómico, uma melhoria do sistema de dupla escuta que não produzisse eco perturbador das conversas, mas que contudo indicasse aos operadores que estão a ser ouvidos.

\section{0 tratamento gestual do ruído/instrução}

19 Neste segundo extracto interessará o modo como uma expressão oral de trabalho, no caso uma instrução dirigida a múltiplos ouvintes e produzida pelo chefe de palco é 
tratada e interiorizada pelo participante na acção como um ruído. Esta sequência é constituída por uma etapa de validação. A validação, por um responsável de agência (também chamado "responsável pelas entregas") ou eventualmente por um supervisor como é aqui o caso, segue-se à etapa de prospecção e de marcação de encontro pela teleoperadora. Após ter explicado ao cliente potencial as condições da oferta ela recolhe "informações do cliente", tais como o endereço, e marca-lhe um encontro com um comercial que se deslocará ao seu domicílio no dia seguinte. A seguir ela passa o seu micro-auscultador a um responsável de agência ou a um supervisor enquanto o cliente potencial está em linha; aquele valida a chamada ao confirmar que o cliente potencial compreendeu bem todas as condições da oferta e do encontro e comunica-lhe ainda quais os documentos necessários para estabelecer o contrato. Este último (Sup) está em comunicação com o cliente potencial (Pro) quando o chefe de palco (CDP) anuncia uma pausa. O anúncio é lançado para a plateia para ser ouvido pelo conjunto dos seus membros (Lan Hing Ting, \& Pentimalli, no prelo).

Para facilitar a leitura da transcrição parece-me pertinente precisar as razões pelas quais a transcrição se apresenta em duas colunas distintas. A primeira é que a conversa telefónica que envolve o supervisor e a sua interlocutora e as trocas (de palavras) ouvidas no palco emergem analiticamente como relevando de quadros de participação (Goffman, 1974) distintos. A recolha de imagens focalizou-se no posto de trabalho em que se encontra o supervisor em funções e em consequência as outras contribuições parecem relevar de um pano de fundo sonoro. Do ponto de vista da cliente e em termos da conversa telefónica à distância, a actividade respeitante à chamada telefónica e a do palco não podem ser analisadas num mesmo nível. Poder-se-ia portanto considerar que a transcrição na coluna "chamada" trata os elementos da conversa potencialmente pertinentes para a cliente distante, na antecena (Goffman, 1973) da relação com a cliente (Frenkel, Korkzynski, \& Tam, 1999). A coluna "palco" diz respeito aos "bastidores", a organização mais global do trabalho do palco, à qual a cliente não deveria ter, idealmente, acesso. A segunda razão é que, a priori, as duas actividades não estão, obrigatoriamente, ligadas, mesmo do ponto de vista dos actores presentes no palco. Transcrever tudo na mesma coluna, com sobreposições, quando se trataria de facto de conversas paralelas, não seria provavelmente adequado em termos de metodologia. Entretanto, sendo colocadas lado a lado com o início de cada parte do ciclo na mesma linha para indicar que começam ao mesmo tempo, tanto a temporalidade da chamada como a actividade no palco são preservadas. A última razão, que acresce à segunda, é de ordem prática por motivos de compreensão e legibilidade da transcrição. 


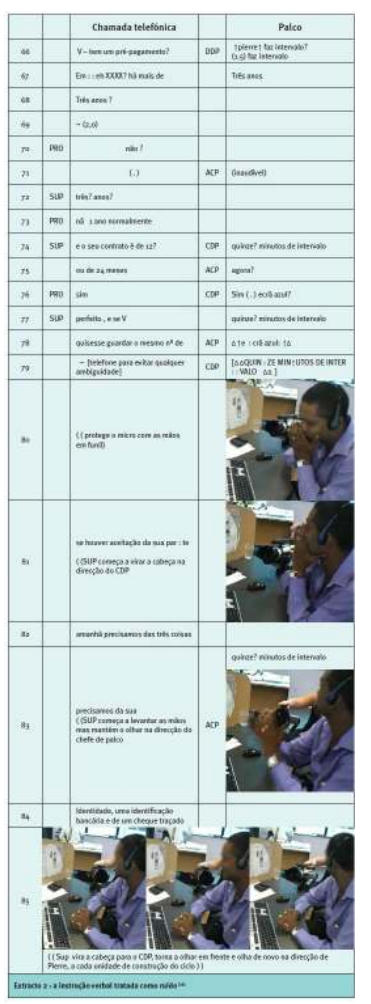

21 Sem pretender substituir os dados originais, a transcrição aqui exposta tenta restituir o melhor da multi-modalidade e da diversidade dos "sons" ou dos "ruídos" perceptíveis no palco e sobretudo a orientação corporal do supervisor. A escolha desta forma de transcrição (Jefferson, 2004) tende pois, pelas razões antes expostas, num primeiro momento, a distinguir as duas actividades. Todavia, estes dois "espaços" em interacção, entrelaçam-se com o anúncio de intervalo dito em voz alta pelo chefe de palco (CDP). A instrução " $\uparrow$ pierre $\uparrow$ faz intervalo ?" que vem, primeiro do director de produção (DDP) (linhas 66 e 67, coluna do palco) é em seguida transmitida pelo chefe de palco ao seu assistente. Após negociação entre o chefe de palco e o assistente-chefe de palco (ACP) entre as linhas 74-77, e uma confirmação pelo chefe de palco) "ya, (.) e ? crã azul ? quinze minutos de pausa" (linhas 76 e 77, coluna palco), o assistente-chefe de palco (ACP) anuncia " $\Delta \mathrm{e}:$ crã azul $\Delta$ " (linha 78). Este anúncio do assistente é completado pelo chefe de palco alto e bom som : "[ $\Delta \Delta$ QUIN : ZE MINUTOS DE INTER : : VALO $\Delta \Delta]$ (linhas 81 e 82, coluna 2). De facto o ecrã azul refere-se à acção de se desligar do posto de trabalho e é completado pelo anúncio da razão de ser da desconexão - a pausa - e da sua duração. A transcrição tenta reproduzir estes fenómenos vocais : " $\Delta$ " para traduzir volume, as maiúsculas para indicar que fala em voz alta para toda a plateia e "” para mostrar a subida de tom. Este aviso dito em voz alta, dirigido a múltiplos receptores de modo a ser ouvido por toda a assistência constitui para a maior parte dos presentes no palco, uma informação pertinente. Em contrapartida é tratado como ruído pelo supervisor em funções. Num gesto incorporizado, com as mãos em forma de funil, protege o micro numa tentativa de isolar a conversa telefónica externa dos elementos sonoros provenientes da sua envolvente próxima de trabalho. Mantém esta posição corporal contraída, as mãos em funil das linhas 79 a 83, enquanto prossegue a conversa com a cliente. Entretanto olha fixamente o chefe de palco (linhas 80 a 84) para tornar visível o seu incómodo e não retira as mãos senão quando se assegura de que aquele 
captou o seu mal-estar e de que não fará outro aviso do género. O seu gesto é, simultaneamente, um gesto prático (impedir que a cliente ouça) e comunicacional (visível pelo chefe de palco). Depois de levantar as mãos mantém, o olhar para o chefe de palco num body torque (Schegloff, 1998), mais um instante, sorrindo. O body torque, segundo a definição de Schegloff, como o desalinhamento da cabeça em relação ao tronco, assinala uma orientação corporal específica e um compromisso diferente do compromisso principal, o da parte inferior do corpo. Só após alguns segundos ele redirecciona a cabeça para o ecrã do computador, antes de uma última olhadela em direcção ao chefe de palco e de retomar a actividade no computador : clicar, validando assim a chamada antes de se desconectar.

Com o incorporizado gesto de mãos e a manutenção do olhar dirigido ao chefe de palco, que tornou voluntariamente visível para este último, o supervisor encara este aviso do chefe de palco como um ruído. Vimos no vídeo, tal como nas imagens que dele retiramos e que são apresentadas neste artigo sob a forma de fotografias inseridas na transcrição, que ambos os participantes se encontram próximos um do outro. 0 volume do aviso, em voz alta, para todo o palco é mais relevante para aqueles que se encontram fisicamente próximo da mesa do chefe de palco, como é o caso deste supervisor. Mesmo que todos ouçam o aviso do chefe de palcoo incómodo sonoro é mais aceitável para os membros situados no fundo da sala. Todavia, apesar de tratar o aviso como ruído, o supervisor não o encara como sonoridade fisicamente prejudicial. Ele não tapa, por exemplo, os ouvidos como é típico das pessoas ao ouvir um foguete (Féraud, no prelo), uma campainha de alarme ou um martelo pneumático. 0 facto de proteger o micro é revelador de que o ruído não é tomado como um constrangimento sonoro fisiológico.

Aquele aviso é percebido e tratado, pelo supervisor, como ruído, essencialmente em termos de conteúdo semântico ; "15 minutos de intervalo" anunciados àquele nível de sonoridade é potencialmente audível pela ouvinte externa que compreende e identifica o aviso como linguagem de trabalho (Drew, \& Heritage, 1992). Além do valor facial, segundo o qual anunciar o intervalo em voz alta daquela maneira seria indelicado, e do facto de que falarem-se a uma distância grande demais é, segundo as normas em vigor, inconveniente, é o "reconhecimento" deste aviso à distância que o supervisor trata como perturbador da sua conversa telefónica em curso. 0 aspecto identificável do aviso opõe-se assim às numerosas intimações dos diferentes teleoperadores em redor do supervisor. Com efeito, cinco outras intimações (linhas 21, 30, 34,38 e 42) via palmas ou estalar de dedos seguem-se às da operadora (na linhas 4 e 14). A mais sonora, a quarta (linha 38) é a do chefe de palco que dá seguimento à das teleoperadores, amplificando-a (Lan Hing Ting, \& Pentimalli, no prelo). Esta intimação atrai mais particularmente a atenção do supervisor que, depois de ter varrido o palco com o olhar, volta a cabeça para o chefe de palco de maneira mais notória. 
Extracto 3 : a instrução verbal tratada como ruído

\begin{tabular}{|c|c|c|c|c|}
\hline & & Chamada telefónica & & Palco \\
\hline 26 & PRO & sim & $\mathrm{x}$ & $X f^{\star}$ HHHh $f$ \\
\hline 27 & SUP & senhora XXXX & & \\
\hline 28 & & sim : encantado? > senhora, eu & & \\
\hline 29 & & $\begin{array}{l}\text { - apresento-me : < ( (volta a } \\
\text { cabeça }))\end{array}$ & & \\
\hline 30 & & $\begin{array}{l}\text { eh sou joel calis ((endireita a } \\
\text { cabeça)) }\end{array}$ & $\mathrm{X}$ & (( palmas-duas vezes $))$ \\
\hline 31 & & responsável pelas entregas? & & \\
\hline 32 & & da sociedade? XXXXX agora?, & \multirow{5}{*}{$x$} & \multirow{5}{*}{$(($ palmas-duas vezes $))$} \\
\hline 33 & & retomo a comunicação & & \\
\hline 34 & & claro para va?lidar alguns & & \\
\hline 35 & & pontos?, - consi:go? & & \\
\hline 36 & & $(($ volta a cabeça $))$ & & \\
\hline
\end{tabular}

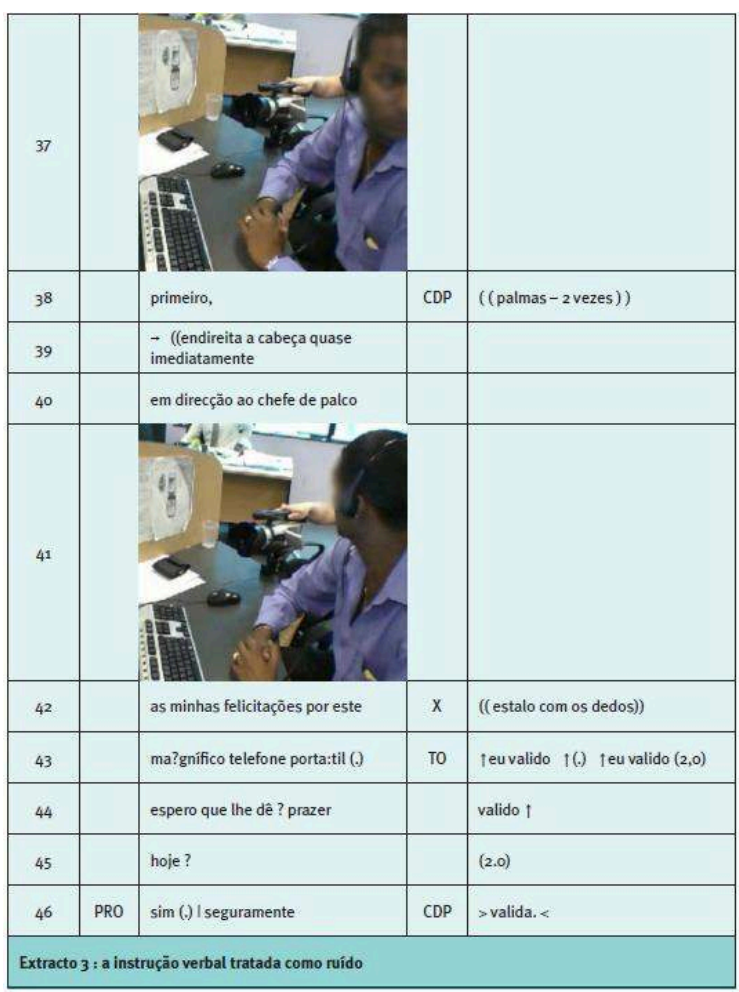

24 As sucessivas intimações e justamente a lançada pelo chefe de palco, têm provavelmente uma intensidade sonora tão elevada como o aviso mas, ao contrário deste último, as intimações não são identificáveis e perceptíveis pela cliente potencial. Por essa razão, as intimações não são incomodativas para o supervisor que não as trata como ruídos mas pelo contrário como verdadeiras intimações ou meios de atrair a 
atenção e chamar os superiores hierárquicos. Há estudos que mostraram que são a fala e as actividades humanas (distractive speech noise) que, em open office, mais desconcentram (Helenius, Keskinen, Haapakangas, \& Hongisto, 2007). Distinguindo quatro tipos de ruído - ruído branco de tipo 2, ruído da circulação rodoviária, palavra não pertinente destituída de sentido e finalmente palavra pertinente significativa Zucchi e Gamberini (2007 : 209) demonstram que são as formas verbais de ruído e mais particularmente a última que constituem uma perturbação em termos de actividades cognitivas. É possível deduzir daí que, identicamente, na actividade dos call centers, caracterizada por uma ecologia de open office, é a palavra pertinente e significativa, compreensível e audível que constitui a forma de "ruído" mais perturbadora.

O aviso é também tratado como ruído dado que se trata aqui de duas envolventes interaccionais distintas em duas colunas restituídas na transcrição: à direita, a envolvente espacial e sonora do palco em que os membros colaboram, em co-presença, em práticas comunicativas potencialmente ruidosas e, à esquerda o espaço interaccional da chamada telefónica externa em que a conversa é mediada pelo dupla telefónica-Informático. No seio desta distinção o espaço de trabalho podia ser considerado como os "bastidores" e o espaço da conversa como sendo o "antecena" como os qualificaria Goffman (1973). Por isso, quando uma conversa de trabalho, interna, tendo lugar no palco, se imiscui na conversa telefónica à distância via características sócio-materiais dos auscultadores, os dois espaços misturam-se enquanto, idealmente, os elementos dos bastidores seriam supostamente aí mantidos. Tornam-se portanto elementos potencialmente perturbadores da conversa e são categorizados como "ruídos", como é o caso para o supervisor referido.

0 momento em que o aviso se situa na sequência da conversa também contribui para o facto de o supervisor o percepcionar como incomodativo. o final da chamada deveria dar aos dois interlocutores a sensação de que se despedem quando nada mais há a dizer, após o adequado despoletar da sequência de encerramento (Schegloff, \& Sacks, 1973). Ora o anúncio de pausa poderia dar à cliente potencial a sensação de que o agente vai dispensar-se de explicações, apressadamente, para poder partir para intervalo o mais rápido possível e portanto de que ela não seria tomada a sério. Do ponto de vista interaccional este género de perturbações poderia ser nocivo para a relação comercial. Além disso, nesse momento da chamada o supervisor está em vias de confirmar o interesse da cliente potencial na oferta ; o ruído perturbador surge exactamente antes de ele lhe comunicar a lista de documentos que ela deveria entregar ao comercial que se vai deslocar ao seu domicílio. Trata-se portanto de um momento importante da chamada, em termos da actividade a levar a cabo. Se a cliente potencial não tomar boa nota da lista de documentos a apresentar ao comercial no dia seguinte, tanto este desperdiça o seu tempo como o contrato não se fecha, caso em que a venda se perde. Quando uma venda se perde não só a teleoperadora não recebe a comissão mas, além disso, um comercial ter-se-á deslocado "para nada". De qualquer modo significa tempo de trabalho e dinheiro perdidos.

No espaço sequencial da chamada - na qual se imiscui quando deveria manter-se em segundo plano - o aviso sonoro é problemático e torna-se um ruído. É tratado como tal pelo supervisor, de forma visível a partir da sua actuação gestual ao proteger o micro com as mãos e pela orientação do olhar, em direcção ao chefe de palco. Todavia este aviso, do ponto de vista dos outros membros do palco, constitui no fundamental uma informação pertinente, em termos de organização da actividade. Participa também da 
alegre dinâmica de partir para intervalo, na qual o supervisor também se inclui : ele sorri enquanto fita o chefe de palco.

\section{Conclusão}

A maior parte das pesquisas incidindo em call centers, quer as sociológicas, com recurso à análise estatística (Taylor, et al., 2003) quer as de segurança medindo os níveis sonoros (Planeau, \& Robinet, 2003) concordam na demonstração de que um call center é um local de trabalho barulhento. Neles, as relações interpessoais não são todavia obrigatoriamente difíceis (Kryter, 1985) nem os constrangimentos sonoros inevitáveis. Este artigo examinou a organização da linguagem e do decurso da acção de um ponto de vista émico (Pyke, 1967 ; Winkin, 1981) e de forma situada, para questionar se a envolvente ruidosa é pertinente para os participantes e de que modo a sua pertinência se torna visível e demonstrável para e pelos intervenientes. As ocorrências sonoras nos dois extractos analisados, trate-se de tematizar verbalmente o eco nos auscultadores (extracto 1) ou do aviso pluri dirigido ao qual o supervisor reage colocando as mãos em funil (extracto 2), são categorizáveis como "ruído", como é visível nos outros participantes e demonstrável pela análise. o "ruído emerge como elemento perturbador seja porque o eco perturba a audibilidade da conversa telefónica, seja porque a instrução pode ser ouvida pela cliente potencial num momento delicado da sequência da conversa, ao imiscuírem-se os bastidores na importante etapa da validação. Nenhum dos dois participantes, cuja acção se descreveu interpreta o ruído como um constrangimento sonoro. Estes dois fenómenos de "ruído" não são plenamente compreensíveis senão tendo em conta o contexto que as faz emergir como tal. Não podem ser generalizáveis para afirmar que o call center constitui uma envolvente ruidosa. Todavia, vistas as sensações de incómodo constatadas, seria possível imaginar uma melhoria do sistema de escuta dupla que não produzisse eco perturbador da conversa mas que no entanto indicasse aos operadores que estão sob escuta. Com efeito, a escuta das chamadas de um operador, introduzindo eco nos auscultadores é uma situação por vezes problemática. Do mesmo modo, a seguir ao meu retorno do terreno, pude observar o uso regular de mensagens sob a forma de janelas surgindo em todos os ecrãs de computador, pluri endereçados ao conjunto do palco para anunciar pausas ou o fim do trabalho. Seria igualmente possível encarar um uso mais regular e uma "usabilidade" (Nielsen, 1993) melhorada dessas ferramentas, sempre tendo em conta que os avisos em voz alta participam de uma certa dinâmica de equipa. De facto o supervisor reconhece esta alegre dinâmica que é o anúncio de intervalo : não se mostra molestado, até sorri ao fitar o chefe de palco que produziu a instrução/ruído. É portanto essencial - quer o objectivo analítico seja uma descrição fina com vista a compreender a emergência do ruído quer uma melhoria do trabalho analisar estas ocorrências tendo em conta a sensibilidade dos participantes à sua envolvente material, ao contexto social, material sequencial e praxiológico. Com efeito, o eco nos auscultadores é ao mesmo tempo um recurso informacional relacionado com o facto de estar sob escuta, como um entrave à audibilidade da comunicação telefónica. Identicamente, o aviso constitui uma informação pertinente para o conjuntodo palco embora constitua, em simultâneo, um incómodo para o supervisor. Tendo em conta estes diferentes pontos de vista, o call center aparece então, não somente como uma 
envolvente ruidosa mas um local de trabalho com os ruídos de actividades socialmente organizadas.

Tabela 1 : Índice das notações da transcrição e das abreviaturas das categorias dos participantes.

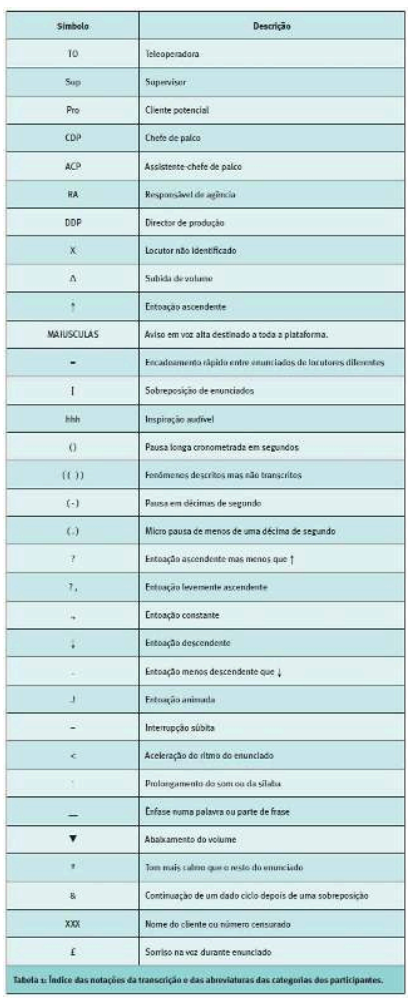

Bannon, L. J. (1991). From human factors to human actors : The role of psychology and human-computer interaction studies in system design. In J. Greenbaum \& M. Kyng (Eds.), Design at work : Cooperative design of computer systems (pp. 25-44). Hillsdale, $\mathrm{NJ}$ : Lawrence Erlbaum Associates.

Béguin, P. (2007). Prendre en compte l'activité de travail pour concevoir. @ctivités, 4(2), 107-14, http://www.activites.org/v4n2/ beguin-FR.pdf

Benchekroun, T. H. (2000). Les espaces de coopération proxémique. In T. H. Benchekroun \& A. Weill-Fassina (Eds.), Le travail collectif : perspectives actuelles en ergonomie (pp. 35-53). Toulouse : Octarès Editions.

Blanquet, J. \& Poupa, M. M. (2007). Fiabiliser, enrichir la relation client en contexte SAV. Actes du 42ème Congrès de la Société d'Ergonomie de Langue Francaise (SaintMalo ; 5-6-7 septembre)

Clayman, H. M. (1995). The dialectic of ethnomethodology. Semiotica, 107(1/2), 105-123.

Crabtree, A. (2003). Designing collaborative systems : A practical guide to ethnography. London : Springer-Verlag.

Datchary, C. \& Licoppe, C. (2007). La multi-activité et ses appuis: l'exemple de la “présence obstinée » des messages dans l'environnement de travail. @ctivités, 4(1), 4-29.

Drew, P. \& Heritage, J. (1992). Analyzing talk at work : an introduction. In 
P. Drew \& J. Heritage (Eds.), Talk at work: interaction in institutional settings (pp. 3-65). Cambridge : Cambridge University Press.

Duranti, A. (2001). Universal and culture-specific properties of gretings. In A. Duranti (Ed.), Linguistic Anthropology: a reader (pp. 208-238). Malden, Mass: Blackwell Publishing.

Féraud, O. (sous presse). Le bruit et la lumière : une anthropologie sonore des pétards et des feux d'artifice à Naples. Ethnographiques. org, 19.

Francis, D. \& Hester, S. (2004). An Invitation to Ethnomethodology : Language, Society and Interaction. London : Sage Publications Frenkel, S., Korczynski, M., A., S. K. \& Tam, M. (1999). On the Front Line: Organization of Work in the Information Economy. Ithaca : Cornell University Press.

Garfinkel, H. (1967). Studies in Ethnomethodology. Englewood Cliffs, $\mathrm{Nj}$ : Prentice Hall

Garfinkel, H. \& Sacks, H. (1970). On formal structures of practical actions. In McKinney \& Tiryakian (Eds.), Theoretical Sociology; Perspectives and Developments (pp. 160-193). New York : Appleton-Century-Crofts.

Goffman, E. (1973). La mise en scène de la vie quotidienne. Paris : Les Editions de Minuit.

Goodwin, C. (1981). Conversatioinal organization: interaction between speakers and hearers. New York : Academic Press.

Goodwin, C. \& Duranti, A. (1992). Rethinking context : an introduction. In A. Duranti \& C. Goodwin (Eds.), Rethinking context: Language as an interactive phenomenon (pp. 1-42). Cambridge : Cambridge University Press.

Goffman, E. (1974). Frame analysis : An essay on the organization of experience. New York : Harper and Row.

Have, P. T. (1999). Doing Conversation Analysis : A Practical Guide. London : SAGE.

Heath, C. \& Hindmarsh, J. (2002). Analysing interaction: Video, ethnography and situated conduct. In T. May (Ed.), Qualitative Research in Action (pp. 99-121). London : Sage.

Heath, C., Knoblauch, H. \& Luff, P. (2000). Technology and Social Interaction: the Emergence of 'workplace Studies'. The British Journal of Sociology, 51(2), 299-320.

50 Heath, C. \& Luff, P. (1992). Collaboration and control: crisis management and multimedia technology in London Underground control rooms. Journal of Computer Supported Cooperative Work, 1, 69-94.

51 Heath, C. \& Luff, P. (Eds.) (2000). Technology in Action. Cambridge : Cambridge University Press.

Helenius, R., Keskinen, E., Haapakangas, A. \& Hongisto, V. (2007). Acoustic environment in finnish offices the summary of questionnaire studies. Paper presented at the 19th International Congress on Acoustics, 2-7 September 2007, Madrid.

53 Hester, S. \& Francis, D. (Eds.). (2000). Local educational order : ethnomethodological studies of knowledge in action. Amsterdam : John Benjamins.

Hughes, J. A., Randall, D. \& Shapiro, D. (1992). Faltering from ethnography to design. Proceedings of the 1992 ACM Conference on Computer-supported cooperative work, 115-122. 
Institut des Métiers de France Telecom, (1999). Les Centres D’appels En France: Synthèse Des Principaux Écrits. Paris : France Telecom

Jefferson, G. (2004). Glossary of transcript symbols with an introduction. In G. H. Lerner (Ed.), Conversation analysis : Studies from the first generation (pp. 13-31). Amsterdam/ Philadelphia : John Benjamins.

Karsenty, L. \& Pavard, B. (1997). Différents niveaux d'analyse du contexte dans l'étude ergonomique du travail collectif. Réseaux, 85, 73-99.

Kensing, F. \& Simonsen, J. (1997). Using ethnography in contextual design. Communications of the ACM, 40(7), 82-88.

Kryter, K. D. (1985). The effects of noise on man. New York : Academic Press.

Lan Hing Ting, K. \& Pentimalli, B. (sous presse). Le “ bruit » comme ressource pour la coopération et la coordination entre téléopérateurs dans les centres d'appels. Ethnographiques.org, 19.

1 Leplat, J. \& Hoc, J. M. (1983). Tâche et activité dans l'analyse psychologique des situations. Cahiers de psychologie cognitive, 3(1), 49-63.

Licoppe, C. \& Relieu, M. (2005). Entre système et conversation. Une approche située de la compétence des téléopérateurs dans les services d'assistance technique. In E. Kessous \& J.L. Metzger (Eds.), Le Travail Avec Les Technologies De L'information (pp. 177199). Paris : Hermès.

3 Lynch, M. (2000). Against Reflexivity as an Academic Virtue and Source of Privileged Knowledge. Theory, Culture, and Society, 17 (3), 27-56. Maynard, D. W. (1980). Placement of topic changes in conversation. Semiotica, 30, 263-290.

Maynard, D. W. (2003). Bad news, good news : Conversational order in everyday talk and clinical settings. Chicago, Ill. ; London : University of Chicago Press.

Mondada, L. (2008). Using video for a sequential and multimodal analysis of social interaction: videotaping institutional telephone calls. Forum Qualitative Sozialforschung / Forum : Qualitative Social Research, 9(3), 88 paragraphs.

Nielsen, J. (1993). Usability Engineering. Boston : Academic Press.

Ombredane, A. \& Faverge, J.-M. (1955). L'analyse du travail: facteur d'économie humaine et de productivité. Paris : PUF.

Planeau, V. \& Robinet, D. (2003). Evaluation De L'exposition Sonore Quotidienne Des Opérateurs De Centres D'appels Téléphoniques. Institut national de recherche et de sécurité NS, 231.

9 Pike, K. L. (1967). Language in relation to a unified theory of the structure of human behavior. The Hague : Mouton.

Relieu, M., Licoppe, C. \& Lan Hing Ting, K. (à paraître). Filmer le travail dans les centres d'appels: le cadrage vidéo et sonore comme mise à l'échelle de l'activité. Actes du Colloque Filmer le travail, Film et Travail, Aix en Provence, 21-24 novembre 2007.

71 Salembier, P. \& Zouinar, M. (2004). Intelligibilité mutuelle et contexte partagé. Inspirations conceptuelles et réductions technologiques. @ctivités, 1(2), 64-85.

Sacks, H. (1992). Lectures on conversation (Edited by Gail Jefferson, with introduction by Emanuel A. Schegloff). Oxford, UK ; Cambridge, Mass : Blackwell. 


\section{Temporalités sonores et interaction
Architecture and Behaviour, 7(1), 63-74} pp. 417-428. (pp. 41-62). Berlin : Springer-Verlag. Society 17(3), 435-458.

Sacks, H., Schegloff, E. \& Jefferson, G. (1974). A simplest systematics for the organization of turn taking for conversation. In J. N. Schenkein (Ed.), Studies in the organization of conversational interaction (pp. 7-55). New York : Academic Press.

Shapiro, D. (1994). The limits of ethnography: Combining social sciences for CSCW. Proceedings to the 1994 ACM Conference on Computer Supported Cooperative Work,

Schegloff, E. A. (1987). Analyzing single episodes of interaction: an exercise in conversation analysis. Social Psychology Quarterly, 50, 101-114.

Schegloff, E. A. (1998). Body Torque. Social Research, 65(3), 535-596. Schegloff, E. A. \& Sacks, H. (1973). Opening up closings. Semiotica, 8, 289-327.

Shapiro, D. (2005). Participatory design : the will to succeed. Proceedings of the 4th decennial conference on Critical computing : between sense and sensibility, 29-38.

Suchman, L. (1987). Plans and situated actions: the problem of humanmachine communication. Cambridge : Cambridge University Press. Suchman, L. (1997). Centers of Coordination : a case and some themes. In L. B. Resnick, Säljö, R. Pontecorvo, C. \& Burge, B. (Eds.), Discourse, tools, and reasoning: essays on situated cognition

Taylor, P., Baldry, C., Bain, P. \& Ellis, V. (2003). 'A unique working environment' : health, sickness and absence mangagement in UK call centres. Work, Employment \&

Thibaud, J. P. (1998). The acoustic embodiment of social practice.

Proceedings of the Conference Stockholm, Hey Listen!, pp. 17-22. Thibaud, J. P. (1991). porties sonores et interaction sociale. Architecture et Comportennent $/$ Whalen, J. (1995). Expert systems versus systems for experts : computeraided dispatch as a support system in real-world environments. In P. Thomas (Ed.), The Social and Interactional Dimensions of Human-Computer Interfaces (pp.161-183). Cambridge : Cambridge University Press.

33 Winkin, Y. (1981). La Nouvelle Communication. Paris : Editions du Seuil. Zimmerman, D. H. (1992). The interactional organization of calls for emergency. In P. Drew, P. \& J. Heritage (Eds.), Talk at work: interaction in institutional settings (pp. 418-469). Cambridge : Cambridge University Press.

Zucchi, A. \& Gamberini, L. (2007). Searching for information on PDA in a naturalistic environment with or without music. PsychNology Journal, 5(2), 207-222.

\section{NOTAS}

1. O Institut National de Recherche et de Sécurité (Planeau, \& Robinet, 2003) consagra diversos documentos à segurança no trabalho e aos meios de melhorar as condições de trabalho em call 
centers, tratando nomeadamente do ruído do trabalho em ecrã, do arranjo dos postos de trabalho e dos métodos de gestão respeitantes às consequências no bem-estar dos operadores.

2. Este qualificativo é usado com prudência dado que qualquer actividade, seja individual ou colectiva não deixa de ser social. As nossas actividades enquanto membros da sociedade são fundamentalmente interaccionais e são enquadradas pelo facto de se ser membro da sociedade e pelas nossas relações com os outros (Francis, \& Hester, 2004). Aliás trata-se, no caso dos call centers, de uma actividade de relação de serviço que se cumpre em interacção com o cliente e a ferramenta informática (Licoppe, \& Relieu, 2005)

3. A accountability (Garfinkel, 1967) a "descritibilidade" e o carácter reconhecível dos acontecimentos do mundo social - constitui um dos conceitos-chave em etnometodologia. Ver os trabalhos de Salembier e Zouinar (2004) que afinaram a noção de "descritibilidade" nas pesquisas conduzidas sobre a cooperação, colocando-a em perspectiva, relacionando-a com a noção de "contexto partilhado" mobilizada pela ergonomia.

4. De carácter polissémico e ubiquitário em ergonomia (Karsenty, \& Pavard, 1997) o contexto é dificilmente definível nos discursos de inspiração etnometodológica (Goodwin, \& Duranti, 1992). Nem por isso é menos essencial para compreender o sentido de um enunciado ou de uma acção (Maynard, 2003) e é hoje largamente reconhecido nas ciências cognitivas.

5. Janela que surge no ecrã do computador. Esta comunicação quase síncrona partilha com os programas de mensagens instantâneas as mesmas características sem que todavia o suporte seja idêntico. Diremos portanto "discussão instantânea".

6. Dado o automatismo das chamadas não é possível prever o momento em que o interlocutor vai atender. Desactivando o microfone os teleoperadores não correm o risco de que o cliente potencial surpreenda a conversa "interna".

7. A primeira etapa da minha etnografia consistiu em ouvir desse modo os teleoperadores. A lista dos diferentes operadores em função aparecia no ecrã e era suficiente clicar no seu nome para os ouvir. Eles sabem que estão a ser escutados justamente por ouvirem o eco.

8. Disponho do conjunto de registos dos telefonemas com os clientes, no qual pude constatá-lo.

9. Saber que Ketty é uma responsável da agência com acesso aos detalhes das conexões dos teleoperadores.

10. Os teleoperadores não podem comunicar em modo de comunicação instantânea senão com os superiores hierárquicos e não entre eles.

11. Nesta transcrição as palavras ou partes de palavra a negrito (bold) correspondem temporalmente à imagem abaixo.

\section{RESUMOS}

Os call centers são considerados, de acordo com estudos de ergonomia e de medicina do trabalho, como envolventes de trabalho ruidosas. Os ruídos percepcionados são diversos : o ruído ambiente - causado sobretudo pelas vozes e o manobrar dos teclados dos numerosos teleoperadores presentes na mesma plataforma - o ruído nos auscultadores, ou os anúncios sonoros destinados a toda essa plataforma. Todavia nenhum membro do palco do call center observado parece percepcionar o ruído ambiente ou o dos auscultadores como um constrangimento sonoro. Tratase de uma habituação aos níveis acústicos ou de uma estruturação da perceptibilidade dos diferentes produções sonoras durante a actividade ? Assim, o estudo etnográfico do ruído nos call centers implica abordá-lo segundo a sua pertinência para a actividade e do ponto de vista dos 
teleoperadores, tendo em conta as contingências da sua produção em situação real de trabalho. Este artigo debruçar-se-á sobre dois extractos - uma queixa respeitante ao eco nos auscultadores e um aviso a toda o palco - combinando uma análise sequencial multimodal dos intercâmbios baseada na transcrição dos registos, com uma mobilização de conhecimentos contextuais do pano de fundo, adquiridos pela etnografia. Ver-se-á como estas duas ocorrências sonoras emergem como "ruídos" pela categorização que delas fazem os participantes na acção.

Los centros de llamadas (call centers) se consideran, de acuerdo con estudios ergonómicos y de medicina del trabajo, como ejemplo de trabajos ruidosos. Los ruidos percibidos puede ser variados : el ruido ambiental, causado, sobre todo, por las voces y los teclados de los numerosos teleoperadores de una misma plataforma; el ruido de los auriculares y/o los anuncios sonoros que se emiten en lugar. Todavía no existen miembros del palco del call center que perciban el ruido ambiental o el de los auriculares como un problema sonoro. ¿Será que estarán habituados a los niveles acústicos o será una reestructuración de la percepción de los diferentes emisores sonoros durante la actividad? De esta forma, un estudio etnográfico sobre el ruido en los call center implica un abordaje de acuerdo con su relación con la actividad y con el punto de vista de los teleoperadores, teniendo en consideración las formas en que ocurre en la situación real de trabajo. El presente artículo estará basado en dos situaciones : una queja relacionada con el eco en los auriculares y un aviso al palco, combinando el análisis secuencial multimodal de los intercambios, basado en la transcripción de los registros, con una movilización de los conocimientos contextuales adquiridos del telón de fondo, como resultado de la etnografía. Se verá cómo estos dos elementos sonoros aparecen como "ruido" debido a que así son categorizados por los que participan en la acción.

Les centres d'appels sont considérés comme des environnements de travail bruyants, selon les études en ergonomie et en médecine du travail. Les bruits perçus sont divers : le bruit ambiant causé principalement par les voix et l'utilisation des claviers des nombreux téléopérateurs présents sur la même plateforme - le bruit au casque, ou les annonces sonores lancées à la cantonade. Pourtant, aucun membre du plateau de centre d'appels observé ne semble s'orienter vers le bruit ambiant, ou le bruit au casque comme astreinte sonore. S'agit-il d'une habituation aux niveaux acoustiques ou d'une structuration de la perceptibilité des différentes productions sonores pendant l'activité ? De ce fait, ethnographier le bruit en centre d'appels implique de l'aborder selon sa pertinence dans l'activité et du point de vue des téléopérateurs, en tenant compte des contingences de sa production en situation de travail réel. Cet article s'intéressera à deux extraits - une plainte concernant un écho au casque et une annonce à la cantonade - en combinant une analyse séquentielle multimodale des échanges basée sur la transcription des enregistrements, à une mobilisation de connaissances contextuelles d'arrièreplan acquises par l'ethnographie. L'on verra comment ces deux occurrences sonores émergent comme "bruits" par la catégorisation qu'en font les participants en action.

Abstract Making an ethnographic study of noise in call centres : a situated analysis of call centre agents' work. Call centres tend to be noisy working environments, as studies in ergonomics and occupational medicine have shown. Noise in call centres can take various forms: ambient background noise - caused mainly by a large number of co-present call centre agents speaking on the phone and typing on their keyboards, high volume in the headset and instructions shouted out to the company at large. However, no employee at the call centre I have been observing seems to regard the ambient noise or the noise in the headset as a problem. Do they get used to these acoustic levels or are they unconsciously structuring the noises they perceive while at work? Making an ethnographic study of noise in call centres therefore means analysing that noise in accordance with its relevance to the activity, bearing in mind the contingencies of its production as it actually occurs, and adopting the actors' standpoint. This paper will examine 
two extracts - a complaint about an echo in the headset and a shouted instruction - combining a multimodal sequential analysis of speech based on transcripts of the recordings with ethnographic background data. We will see how these two sound occurrences emerge as "noises" because of the way the participants in the action categorize them.

ÍNDICE

Palabras claves: call center, ruido, video-etnografía, enfoque emic, descripción

Keywords: call center, noise, video ethnography, emic approach, accountability

Palavras-chave: call center, ruído, vídeo-etnografia, abordagem émica, descritibilidade

Mots-clés: centre d'appels, bruit, ethnographie vidéo, approche émique, descriptibilité

\section{AUTORES}

\section{KARINE LAN HING TING}

Département Sciences Economiques et Sociales - Telecom ParisTech 2229 route des Crêtes, 06560, Sophia Antipolis, France

karine.lanhing ting@telecom-paristech.fr 